\title{
DRIVING COMFORT ASSISTANCE SYSTEM CONSIDERING TWO SENSORS DATA
}

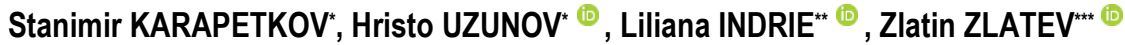 \\ "Technical University of Sofia, Faculty and College of Sliven, Sliven 59 Burgasko Shose Blvd 59, Bulgaria \\ *University of Oradea, Faculty of Energy Engineering and Industrial Management, Department of Textiles, \\ Leather and Industrial Management, B.St.Delavrancea Str., no. 4, 410058, Oradea, Romania, \\ ***Trakia university, Faculty of Technics and technologies, 38 Graf Ignatiev str., 8602, Yambol, Bulgaria \\ skarapetkov@yahoo.com, hvuzunov@gmail.com, liliindrie@yahoo.com, zlatin.zlatev@trakia-uni.bg
}

received 22 March 2020, revised 7 July 2021, accepted 12 July 2021

\begin{abstract}
Abstarct: In the present work, a system using data from two sensors located next to the driver and to the mass centre of the bus is proposed. Three degrees of discomfort have been used - comfortable, moderately uncomfortable and very uncomfortable. These levels are set out in the questionnaire. A survey was conducted. Respondents were selected between the ages of 14 and 65 and were divided into three age groups - adults, middle-aged and young. Accelerometer systems with MPU-6500 (TDK InvenSense Corp.) sensors are used. A correlation method (CORR) and sequentially improving estimation methods are used for feature selection, which significantly reduce the number of combinations of features obtained. Selected sensor data is entered into feature vectors. These vectors are reduced by principal component analysis. Predictive models have been created that take into account the age of passengers. The use of data from two sensors and separation of the passengers according their age, leads to an increase in the accuracy of predicting passengers discomfort level (DL) of up to $98 \%$. These results can be used to evaluate and guide the vehicle driver in order to improve his driving style. In addition, the simplified interface does not distract the driver from the road conditions. The results obtained can lead to an improvement in the parameters of the transport process, which covers the interest of the carrier related to the efficient use of vehicles, and hence the reduction of fuel consumption and harmful emissions. However, it should be recommended that, when developing systems to ensure comfort of travel, adjustments should be made to suit the age group of passengers carried on public transport buses.
\end{abstract}

Key words: stated preference survey, predictive model, customer satisfaction, passenger comfort, passenger service, driver assistance system

\section{INTRODUCTION}

The deterioration of the comfort of traveling in vehicles is due to vibrations, noise and ambient temperature. Drivers' poor driving experience makes the public transportation system less attractive (Vrcan et al., 2011; HaoLiang et al., 2018).

The regulatory documents (ISO, 1978) mainly address the vertical vibration leading to a strong sense of discomfort in commuters. Research into the vertical stability of the passenger is also the subject of scientific research. Improvements in train travel have been explored (Sharma et al., 2018), and also in sea and river passenger transport ships (Kim et al., 2014).

In Bulgaria, which is in the European Union, bus is one of the main methods of public transport in urban and interurban environments (Tsvetkova, 2017). From the available literature, there are known solutions related to attempts to improve travel comfort. Tab. 1 summarises the more commonly used methods for improving the comfort of public transport.

Tab. 1. Methods for improving the comfort of passengers in public transport vehicles

\begin{tabular}{|l|l|l|l|}
\hline \multicolumn{1}{|c|}{ Method } & \multicolumn{1}{c|}{ Advantages } & \multicolumn{1}{c|}{ Disadvantages } & \multicolumn{1}{c|}{ Reference } \\
\hline $\begin{array}{l}\text { Active seat } \\
\text { suspension }\end{array}$ & $\begin{array}{l}\text { It works individually for each passenger, feed- } \\
\text { back with different sensors. }\end{array}$ & $\begin{array}{l}\text { Low stroke of the actuator, depends on the weight } \\
\text { of the passenger, high cost of realisation. }\end{array}$ & $\begin{array}{l}\text { Ikeda et al., 2018; Sikora, } \\
2018\end{array}$ \\
\hline $\begin{array}{l}\text { Active bus } \\
\text { suspension }\end{array}$ & $\begin{array}{l}\text { Long stroke of the actuator, built by serial bus } \\
\text { manufacturers, feedback with different sensors. }\end{array}$ & $\begin{array}{l}\text { Pneumatic or hydraulic pump with high power } \\
\text { consumption is required. }\end{array}$ & $\begin{array}{l}\text { Jurkiewicz et al., 2017; } \\
\text { Long et al., 2018 }\end{array}$ \\
\hline $\begin{array}{l}\text { Driver assistant } \\
\text { systems }\end{array}$ & $\begin{array}{l}\text { Opportunity for software realisation on a mobile } \\
\text { phone. }\end{array}$ & $\begin{array}{l}\text { The system is not active, it depends on the driver's } \\
\text { level of experience. }\end{array}$ & Stoichkov, 2013 \\
\hline
\end{tabular}

Driver-assisted systems have very good potential than the other two active suspension methods. They can be implemented on a mobile phone using the sensors of this device. They can also be applied to older bus models that do not have active suspension systems.
Solutions are known using the sensors available in the mobile phone. Combining their data gives better results than using an accelerometer alone. The advantage of these systems is that when one of the sensors fails, the operation of the system can continue with data from the other sensors. A major drawback of 
the method is that such a method can only be used for a limited period of time after the failure of a major sensor in the system (Stoichkov, 2013).

The decision to use neural networks is made by car and mannequins (Kim eta al., 2019). The disadvantage of this type of system is that it uses complex computational procedures and is suitable for operation in a controlled environment. It is necessary to propose a system that is suitable for real-world application of urban transport. The analysis made shows that the appropriate classification methods are those that use simplified calculation procedures, can be applied by technical means, and that can be placed directly on public transport buses because they speed up the calculation process and reduce the system response time.

It is not clear from the available publications whether the age of travellers is important for the comfort of travel. Such an analysis needs to be done.

The purpose of the article is to evaluate the possibility of improving travel comfort by using data from two sensor systems, depending on the age of the passengers.

\section{MATERIAL AND METHODS}

Iveco Poker Bus (FIAT-IVECO S.p.A.) is used. The bus has a total length of $7.5 \mathrm{~m}$. Accelerometer systems with MPU-6500 (TDK InvenSense Corp.) sensors are used. The systems are mounted in protective housings. The connection between them is via Bluetooth communication. HC-06 modules are used. The module provides Bluetooth 2.0 connection at a speed of $2,400 \mathrm{bit} / \mathrm{s}$. The first sensor system is located next to the driver and the second near the bus centre.

Fig. 1 shows a block diagram of the sensor system used. This scheme is applicable to both systems installed near the driver and to the centre of mass of the bus.

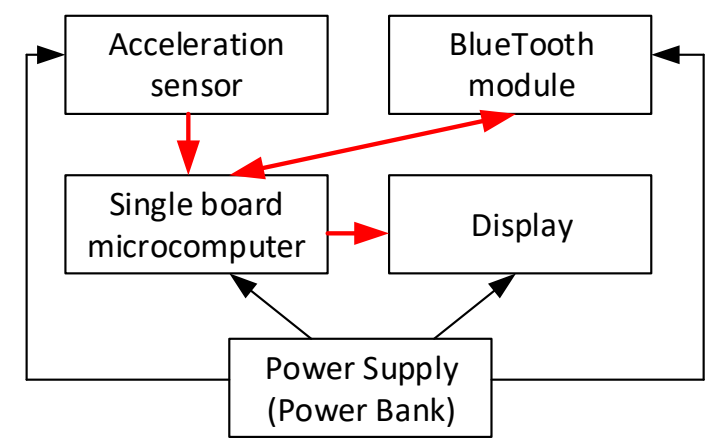

Fig. 1. Block-diagram of a measurement system

Fig. 2 shows a schematic diagram of the experimental layout, with the arrangement of the sensor systems used.

The designations of accelerations along the sensor-driver axes are: $X, Y, Z\left(\mathrm{~m} / \mathrm{s}^{2}\right)$ - for linear accelerations; $A, B, C$ (rad/s) -for angular accelerations. The axes of the sensor to the centre of mass of the bus are: X1, Y1, Z1 - for linear accelerations; A1, B1, C1 - for angular accelerations. The determination of the angular acceleration values on the rotary axes is calculated. This option is preferred because the gyroscopic sensor that is inserted into the MPU-6500 sensor has the disadvantage of obtaining a so-called 'drift' upon measurement (Li et al., 2019). The determination of the angular acceleration values is made by the following mathematical relations:

$$
\begin{aligned}
& A=\operatorname{atan}(Y, Z), \mathrm{rad} / \mathrm{s} \\
& B=\operatorname{atan}(X, Z), \mathrm{rad} / \mathrm{s} \\
& C=\operatorname{atan}(X, Y), \mathrm{rad} / \mathrm{s}
\end{aligned}
$$

These calculations are made for both sensor systems used.

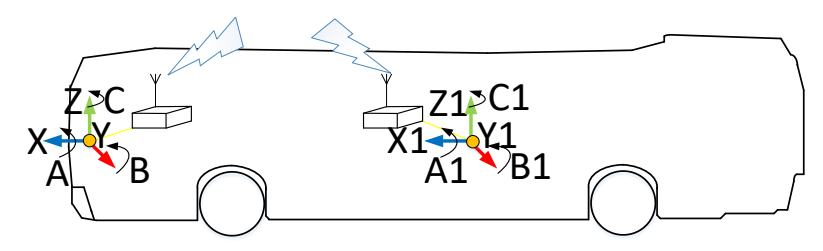

Fig. 2. Experimental setup - general view

Attempts were made in the light-part of day. Meteorological conditions are free of precipitation, clear, sunny weather, ambient temperature $17^{\circ} \mathrm{C}$ and relative humidity $50 \% \mathrm{RH}$. Location of measurements are Tenevo Airport, Tundja Municipality, Bulgaria.

Based on the available literature (Smith et al., 2006), many data are needed and many people are interviewed to obtain objective results for travel comfort. Such analyses are only achievable under controlled and laboratory conditions with pre-prepared respondents. For this reason, the survey developed contains only disaggregated levels of discomfort. Three degrees of discomfort have been used - comfortable, moderately uncomfortable and very uncomfortable. These levels are set out in the questionnaire. The graphics used are with Creative Commons CCO (https://pixabay.com).

A survey was conducted. Respondents were selected between the ages of 14 and 65, and were divided into three age groups - adults, middle-aged and young. Before completing the survey, a clarification is made as to what each degree of discomfort means, which should be noted after each manoeuvre.

The following methods have been used to select features describing the degree of discomfort (Su et al., 2017):

- Correlation method (CORR). Correlation dependence allows one to look for unknown links between features that describe discomfort. In the selection of features, those that have the least possible correlation with each other are sought;

- Method for selecting regression features by analysis of adjacent components (FSRNCA). The algorithm is suitable for selecting features for regression analysis;

- Method for ranking significant forecasting parameters (RELIEFF). The method is a selection function using the ReliefF algorithm for classification and the RReliefF algorithm for regression. This algorithm works well when evaluating the significance of characteristics for distance-based models;

- Weight averages obtained from the feature selection methods. The arithmetic mean of the weights of the features was used.

Principal Components (PCs) obtained by Principal Component Analysis were used to reduce the volume of feature vector data (Mladenov et al., 2015).

An initial model was used to describe the relationship between the main components and the degree of discomfort of the type:

The model coefficients are analysed, depending on the $p$-level value, for each of them. Non-informative coefficients are rejected by the model.

The residuals have been analysed (Tasev et al., 2011), which 
are determined by the difference between the model values and the actual values.

The accuracy of the predictive models is estimated on the basis of statistical parameters. The coefficient of determination (R2), sum of squares of error (SSE) and root mean square error (RMSE) were used as the criteria for model evaluation.

The validation of the results obtained was done with data not used in the previous measurements. Mainly nonlinear manoeuvres are used - left and right turns, as well as reverse turns.

All data were processed at a level of significance $\alpha=0.05$.

\section{RESULTS AND DISCUSSION}

As a result of the calculations and analysis of results, the developed system is presented in general form. Selection methods for feature vectors by which passengers discomfort are predicted, depending on the age of the travellers. Predictive models have been developed. A system for indicating the degree of discomfort is proposed. Validation of the proposed system has been made. The results obtained are compared with those of the available literature.

Fig. 3 shows the sensor devices mounted next to the driver and to the centre of mass of the bus.
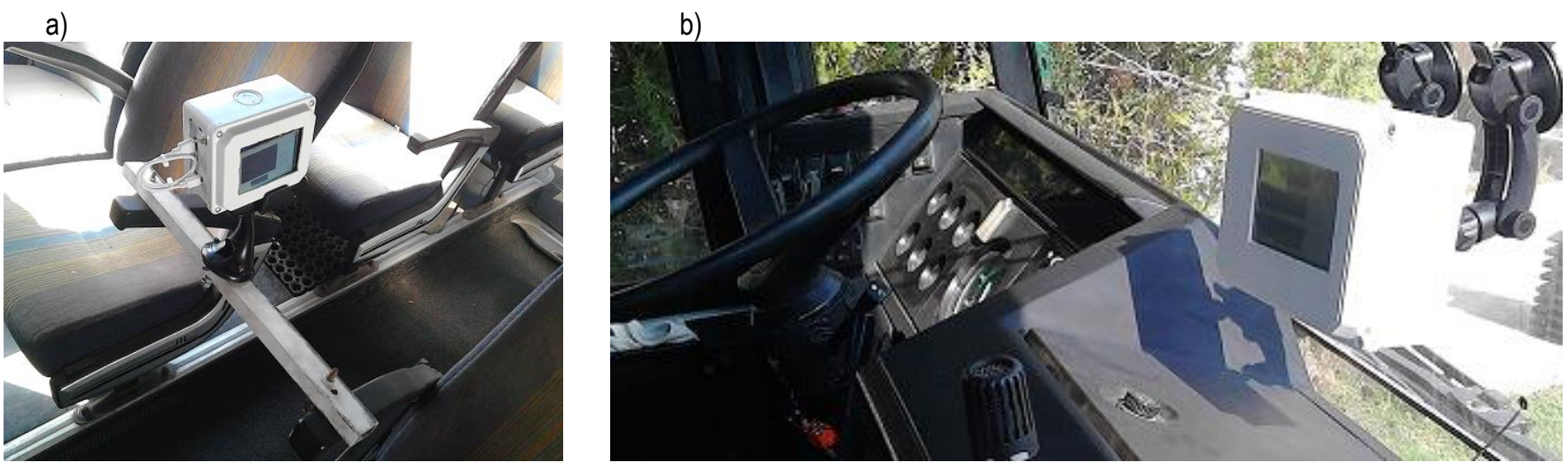

Fig. 3. Measuring devices - general view: (a) a measuring device installed near the mass centre of the bus,

(b) a measuring device installed near the bus driver

Tab. 2 lists data for selected feature vectors. It can be seen that, by the RELIEFF method ( 6 features), the same traits were selected for all age groups according to which the degree of discomfort can be predicted. The highest number of traits were selected by the FSRNCA method (6-10 features), followed by the CORR method (4-7 features).

Tab. 2. Selected feature vectors

\begin{tabular}{|c|c|c|c|}
\hline $\begin{array}{c}\text { Age } \\
\text { group }\end{array}$ & Method & $\begin{array}{l}\text { Feature } \\
\text { vector }\end{array}$ & Selected features \\
\hline \multirow{3}{*}{ Old (0) } & CORR & OFV1 & $X, Y, A, B, X 1, B 1, C 1$ \\
\hline & FSRNCA & OFV2 & $\mathrm{X}, \mathrm{Y}, \mathrm{A}, \mathrm{B}, \mathrm{C}, \mathrm{X} 1, \mathrm{Z1}, \mathrm{A} 1, \mathrm{~B} 1$ \\
\hline & RELIEFF & OFV3 & $\mathrm{Z}, \mathrm{C}, \mathrm{X} 1, \mathrm{Y} 1, \mathrm{Z1}$ \\
\hline \multirow{3}{*}{ MA } & CORR & MFV1 & $\mathrm{C}, \mathrm{Y} 1, \mathrm{~A} 1, \mathrm{C} 1$ \\
\hline & FSRNCA & MFV2 & $\mathrm{Y}, \mathrm{A}, \mathrm{C}, \mathrm{X} 1, \mathrm{Y} 1, \mathrm{Z1}, \mathrm{A} 1, \mathrm{C} 1$ \\
\hline & RELIEFF & MFV3 & $\mathrm{Z}, \mathrm{C}, \mathrm{X} 1, \mathrm{Y} 1, \mathrm{Z1}$ \\
\hline \multirow{3}{*}{$\begin{array}{c}\text { Young } \\
(Y)\end{array}$} & CORR & YFV1 & $\mathrm{Z}, \mathrm{B}, \mathrm{C}, \mathrm{Y} 1, \mathrm{~A} 1$ \\
\hline & FSRNCA & YFV2 & $\mathrm{X}, \mathrm{Y}, \mathrm{Z}, \mathrm{A}, \mathrm{B}, \mathrm{C}, \mathrm{X} 1, \mathrm{Y1}, \mathrm{Z1}, \mathrm{C} 1$ \\
\hline & RELIEFF & YFV3 & $\mathrm{Z}, \mathrm{C}, \mathrm{X} 1, \mathrm{Y} 1, \mathrm{Z1}$ \\
\hline \multirow{3}{*}{$\begin{array}{l}\text { Averaged } \\
\text { (A) }\end{array}$} & CORR & AFV1 & $\mathrm{X}, \mathrm{C}, \mathrm{A} 1, \mathrm{C} 1$ \\
\hline & FSRNCA & AFV2 & $\mathrm{X}, \mathrm{B}, \mathrm{C}, \mathrm{X} 1, \mathrm{Z1}, \mathrm{A} 1$ \\
\hline & RELIEFF & AFV3 & $\mathrm{Z}, \mathrm{C}, \mathrm{X} 1, \mathrm{Y} 1, \mathrm{Z1}$ \\
\hline
\end{tabular}

CORR, correlation method; FSRNCA, method for selecting regression features by analysis of adjacent components; MA, middle aged

Tab. 3 shows the results of preliminary analyses of passengers' discomfort, depending on the age of the respondents. Two major components describe with sufficient accuracy over $95 \%$ of the variation in feature vectors. Results of averaged $(A)$ travel comfort data are also presented. The use of average passenger discomfort data does not show sufficient accuracy to predict it. It is seen that the separation of the data by age groups shows an increase in the values of the coefficient of determination and the reduction of errors.

Tab. 3. PCR results for predicting passengers' discomfort

\begin{tabular}{|c|c|c|r|c|c|c|r|}
\hline $\begin{array}{c}\text { Feature } \\
\text { vector }\end{array}$ & $\mathbf{R}^{\mathbf{2}}$ & SSE & RMSE & $\begin{array}{c}\text { Feature } \\
\text { vector }\end{array}$ & $\mathbf{R}^{\mathbf{2}}$ & SSE & RMSE \\
\hline OFV1 & 0.95 & 1.06 & 0.29 & YFV1 & 0.95 & $0, .81$ & 0.25 \\
\hline OFV2 & 0.98 & 0.49 & 0.19 & YFV2 & 0.99 & 0.19 & 0.12 \\
\hline OFV3 & 0.95 & 0.59 & 0.29 & YFV3 & 0.93 & 1.07 & 0.29 \\
\hline MFV1 & 0.94 & 1.39 & 0.33 & AFV1 & 0.88 & 1.27 & 0.71 \\
\hline MFV2 & 0.96 & 1.04 & 0.28 & AFV2 & 0.89 & 0.84 & 0.25 \\
\hline MFV3 & 0.94 & 1.38 & 0.33 & AFV3 & 0.88 & 0.97 & 0.57 \\
\hline
\end{tabular}

$\mathrm{PCR}$, principal component regression; RMSE, root mean square error; SSE, sum of squares of error

The selected feature vectors, reduced by the principal component analysis method, were used to construct models for predicting the degree of discomfort for three age groups of travellers. After removing the insignificant coefficients from the base model that have $p$-Value $\gg \mathrm{a}$, it has been found that the relationship between travel discomfort and major components of the feature vectors can be described by the following models: 
OFV2

$$
D=2,31+0,99 \cdot P C 1-0,72 \cdot P C 2-0,01 \cdot P C 1^{2}-0,55 \cdot P C 2^{2}
$$

$\mathrm{R}^{2}=0,98$

SSE $=0,01$

RMSE $=0,02$

$R^{2}=0,98$

MFV2

$$
D=2,06+1,12 \cdot P C 1-1 \cdot 19 \cdot P C 2-0,13 \cdot P C 1 \cdot P C 2
$$

SSE $=0,04$

RMSE $=0,02$

$\mathrm{R}^{2}=0,98$

YFV2

$$
D=2,08+1,06 \cdot P C 1-1,51 \cdot P C 2-0,04 \cdot P C 1^{2}
$$

SSE $=0,02$

RMSE $=0,05$

Low standard error values are observed. The coefficients of all models are significant because the $p$-value is much less than the accepted level of significance $a=0.05$.

SSE and RMSE error values are low. The results show that the models obtained describe a significant part of the change in the degree of discomfort in travel, depending on the age group of travellers.

These estimates are not a sufficient criterion for evaluating the model. A residuals analysis needs to be done.

Residuals analysis shows that the models obtained are adequate. When analysing the residuals, there is a lack of systematic deviation of the actual data from the theoretical data, which is a sign of their normal distribution. The analysis of standardised coefficients shows that the first major component of the feature vectors has a significantly greater influence on the predictive power of the models.

Based on the models obtained, three degrees of discomfort have been defined, which can be used in driver signalling by visual indication. The display is divided into three levels - green, yellow and blue, depending on the level of discomfort. Fig. 4 shows the defined degrees of discomfort.
3

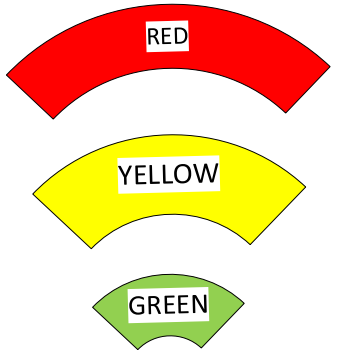

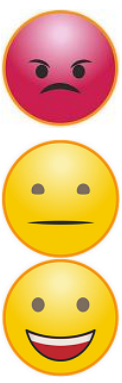

Strongly uncomfortable

\section{Moderate uncom-} fortable

Comfortable

\begin{tabular}{|c|c|c|c|c|c|c|c|c|c|c|}
\hline \multirow{2}{*}{\multicolumn{2}{|c|}{$\begin{array}{c}\mathrm{M} \\
\mathrm{V}, \mathrm{km} / \mathrm{h}\end{array}$}} & \multicolumn{3}{|c|}{ M1, DL } & \multicolumn{3}{|c|}{ M2, DL } & \multicolumn{3}{|c|}{ M3, DL } \\
\hline & & 40 & 50 & 60 & 40 & 50 & 60 & 40 & 50 & 60 \\
\hline \multirow{2}{*}{0} & $S$ & 1 & 2 & 3 & 1 & 2 & 3 & 1 & 2 & 3 \\
\hline & $R$ & 1 & 2 & 3 & 1 & 3 & 3 & 2 & 2 & 3 \\
\hline \multirow{2}{*}{ MA } & $S$ & 1 & 1 & 3 & 1 & 1 & 3 & 1 & 1 & 3 \\
\hline & $R$ & 1 & 1 & 2 & 1 & 1 & 2 & 1 & 1 & 2 \\
\hline \multirow[b]{2}{*}{ Y } & $S$ & 1 & 2 & 3 & 1 & 2 & 3 & 1 & 2 & 3 \\
\hline & $R$ & 1 & 1 & 2 & 1 & 1 & 2 & 1 & 1 & 2 \\
\hline
\end{tabular}

Fig. 4. Indication of the level of discomfort

Tab. 4. Results of system validation

$\mathrm{DL}$, discomfort level; MA, middle aged; M-manoeuvre; $\mathrm{O}$, old; R, respondents; S, system; V-speed; Y-young
Tab. 4 shows the results of system validation. The following manoeuvres were performed at speeds of $40 \mathrm{~km} / \mathrm{h}, 50 \mathrm{~km} / \mathrm{h}$ and $60 \mathrm{~km} / \mathrm{h}$ : M1-linear acceleration; M2-curvilinear acceleration; M3curved slow-down acceleration. The levels of discomfort shown were obtained from a survey of respondents who participated in the previous stages of the survey. Three degrees of discomfort have been defined. The degree of discomfort reported by the system and those of the respondents was also reported. It can be seen that the degree of discomfort determined by the system and the respondents' answers coincide with a difference of up to $5 \%$.

The results obtained confirm, supplement, and refine those reported in the available literature. The proposed model for predicting the degree of discomfort by Ivanov et al. (2019) can be used to predict the degree of discomfort with an accuracy of up to $87 \%$. The models proposed in this paper, depending on the age of the respondents, increase this accuracy to $98 \%$. The results presented by lkeda et al. [8], where the authors evaluate the degree of discomfort in one respondent, mainly take into account the vertical vibration only. Kim et al. (2014) proposed a system using neural networks. Despite the many factors they used in their model, they achieved $70 \%$ accuracy only. Moreover, the neural network method used made their system slow and unsuitable for real-world public transport applications. Same problem also happened with Rekabdar et al. (2018). The system proposed in this paper eliminates this shortcoming by using simplified computing procedures that are suitable for use in a real public transport environment. The influence of the length of the vehicle is also taken into account in the present work. Regardless of the results obtained, which, to one degree or another, improve and complement the well-known travel comfort solutions, and research should continue towards the creation of a generalised model that takes into account the factors such as age of travellers, atmospheric, road conditions, and the particularities of the urban environment in which these systems are implemented. As demonstrated (Stoichkov, 2013), improving travel comfort and proper bus handling indirectly leads to a reduction in fuel consumption, prolongs the life of vehicles and also reduces harmful emissions to the environment.

\section{CONCLUSIONS AND PROSPECTS FOR FURTHER RESEARCH}

The results obtained in this paper confirm, supplement and improve the parameters mentioned in the available published literature. 
Models have been obtained for predicting travel comfort, depending on the age of travellers. Separation of passengers into age groups has been found to improve the accuracy of prediction of the discomfort rate by up to $98 \%$. Due to the large deviations of the averaged analytical models, it is not appropriate to use an averaged model when predicting travel comfort. This means that individual models must be designed for each age group.

In the present work, a three-level discomfort indication system is proposed. These results can be used to evaluate and guide the vehicle driver in order to improve his driving style. In addition, the simplified interface does not distract the driver from the road conditions. The results obtained can lead to an improvement in the parameters of the transport process, which covers the interest of the carrier related to the efficient use of vehicles by the reduction of fuel consumption as well as in reduction of harmful emissions. However, it should be recommended that, when developing systems to ensure comfort of travel, adjustments should be made to suit the age group of passengers carried by public transport buses.

\section{REFERENCES}

1. HaoLiang G., XiHui M., XiaoYong Y., Kai L. (2018), Research on the influence of virtual modeling and testing-based rubber track system on vibration performance of engineering vehicles, Engineering Review, Vol. 38, No. 3, 288-295.

2. Ikeda K., Endo A., Minowa R., Narita T., Kato H. (2018), Ride comfort control system considering physiological and psychological characteristics: effect of masking on vertical vibration on passengers, Actuators, Vol. 7, 42, 1-13.

3. International Organization for Standardization (1978), Guide for the evaluation of human exposure to whole-body vibration, ISO 2631; ISO: Geneva, Switzerland.

4. Ivanov A., Zlatev Z. (2019), Development and research of information system elements for passengers drive comfort improvement, Cybernetics and information technologies, Vol. 19, No. 4, 101-115.

5. Jurkiewicz A., Kowal J., Zając K. (2017), Sky-hook control and Kalman filtering in nonlinear model of tracked vehicle suspension system, Acta mechanica et automatica, Vol. 11, No. 3, 222-228.

6. Kim D., Jeong M., Bae B., Ahn C. (2019), Design of a human evaluator model for the ride comfort of vehicle on a speed bump using a neural artistic style extraction, Sensors, Vol. 19, 1-13.

7. Kim J., Kim Y. (2014), Time-domain analysis of passenger comfort on cruise ships under motion responses in waves, Proceedings of the Institution of Mechanical Engineers, Part M: Journal of Engineering for the Maritime Environment, Vol. 228, No. 4, 331-347.

8. Li S., Gao Y., Meng G., Wang G., Guan L. (2019), Accelerometerbased gyroscope drift compensation approach in a dual-axial stabilization platform, Electronics, Vol. 8, Art. 594, 1-12.
9. Long L., Quynh L., Cuong B. (2018), Study on the influence of bus suspension parameters on ride comfort, Vibroengineering Procedia, Vol. 21, 77-82.

10. Mladenov M., Penchev S., Deyanov M. (2015), Complex assessment of food products quality using analysis of visual images, spectrophotometric and hyperspectral characteristics, International Journal of Engineering and Innovative Technology (IJEIT), Vol. 4, No. 12, 23-32.

11. Rekabdar B., Mousas C. (2018), Dilated convolutional neural network for predicting driver's activity, 21st International Conference on Intelligent Transportation Systems (ITSC), Maui, Hawaii, USA, November 4-7, 3245-3250.

12. Sharma S., Kumar A. (2018), Ride comfort of a higher speed rail vehicle using a magnetorheological suspension system, Proceedings of the Institution of Mechanical Engineers, Part K: Journal of MultiBody Dynamics, Vol. 232, No. 1, 32-48.

13. Sikora M. (2018), Modeling and operational analysis of an automotive shock absorber with a tuned mass damper, Acta mechanica et automatic, Vol. 12, No. 3, 243-251.

14. Smith D., Andrews D., Wawrow P. (2006), Development and evaluation of the Automotive Seating Discomfort Questionnaire (ASDQ), International journal of industrial ergonomics, Vol. 36, 141-149.

15. Stoichkov R. (2013), Android smartphone application for driving style recognition, Thesis, Institute for Media Technology, Department of Electrical Engineering and Information Technology, Munih, Germany.

16. Su W-H., He H-J., Sun D-W. (2017), Non-Destructive and rapid evaluation of staple foods quality by using spectroscopic techniques: A review, Critical reviews in food science and nutrition, Vol. 57, No. 5, 1039-1051.

17. Tasev G., Krastev K. (2011), Exploration of mathematical model for optimization of frequency of diagnosis of the elements of machines, Proceedings of The 11th International Conference, Reliability and statistics in transportation and communication, Latvia, 115-119.

18. Tsvetkova S. (2017), Improving the quality of passenger transport in the city of Sofia by implementing intelligent transport systems, Economic and Social Alternatives, No. 4, 29-42, (in Bulgarian).

19. Vrcan Ž., Siminiati D., Lovrin, N. (2011), Design proposal for a hydrostatic city bus transmission, Engineering Review, Vol. 31, No. 2, 81-89.

Acknowledgement: This work was partially supported by the Bulgarian Ministry of Education and Science under the National Research Programme 'Healthy Foods for a Strong Bio-Economy and Quality of Life' approved by DCM \#577 / 17.08.2018".

Hristo Uzunov: (iD https://orcid.org/0000-0003-2229-2828

Liliana Indrie: (D) https://orcid.org/0000-0002-7094-4790

Zlatin Zlatev: (iD https://orcid.org/0000-0003-3080-5048 